\title{
PENGGUNAAN MODEL PICTURE AND PICTURE BERBASIS MULTIMEDIA DENGAN MENGINTERNALISASI PENDIDIKAN KARAKTER PADA PELAJARAN PENDIDIKAN KEWARGANEGARAAN
}

\author{
Dewi Afriany Susanti
}

Dosen Universitas Quality Medan, Email : dewigtgs@gmail.com

Diterima 20 Mei 2017, disetujui untuk publikasi 28 Juli 2017

\begin{abstract}
Abstrak Penelitian ini bertujuan untuk mengetahui penggunaan Model Picture and Picture menggunakan multimedia dengan menginternalisasi pendidikan karakter pada mata pelajaran Pendidikan Kewarganegaraan materi Lambang Negara. Subjek dalam penelitian ini adalah siswa kelas tiga SD Negeri 048232 Kabanjahe yang berjumlah 49 siswa dan sebagai objek adalah peningkatan pembelajaran pada materi Lambang Negara dengan menggunakan model gambar dan gambar berdasarkan multimedia. Teknik Pengumpulan Data adalah Lembar Pengamatan Guru dan Lembar Observasi kegiatan siswa. Berdasarkan hasil penelitian yang telah dilakukan maka pelaksanaan kegiatan pembelajaran guru ada 80\% (kategori baik), pelaksanaan kegiatan pembelajaran 87 siswa (kategori baik), dan hasil belajar siswa 85\% secara klasik, dan nilai rata-rata 82. Dari hasil penelitian ini dapat disimpulkan bahwa pelaksanaan pembelajaran dimasukkan ke dalam kategori baik, dan hasil belajar siswa telah meningkat dan tuntas secara klasik dengan menggunakan model Picture and picture berbasis multimedia pada mata pelajaran Pendidikan Kewarganegaraan.
\end{abstract}

Kata kunci:

Model Picture and

picture, hasil belajar, Lambang Negara

\section{Pendahuluan}

Pendidikan memiliki peran yang sangat penting dalam kehidupan manusia. Pendidikan merupakan proses pengubahan sikap seseorang dalam jangka panjang. Pendidikan merupakan cara untuk meningkatkan kualitas sumber daya manusia (SDM). Menurut Undang-Undang Republik Indonesia No.12 Tahun 2012, pendidikan adalah suatu usaha sadar dan terencana untuk mewujudkan suasana belajar dan pembelajaran agar peserta didik secara aktif mengembangkan potensi dirinya untuk memiliki kekuatan spritual keagamaan, pengendalian diri, kepribadian, kecerdasan dan akhlak mulia.

Pendidikan

kewarganegaraan merupakan mata pelajaran yang digunakan sebagai wahana untuk mengembangkan dan melestarikan nilai luhur dan moral yang berakar pada budaya bangsa Indonesia. Nilai luhur moral ini diwujudakan dalam bentuk perilaku kehidupan siswa sehari-hari, baik sebagai individu maupun sebagai mahluk sosial di tengah masyarakat, dan mahluk ciptaan Tuhan Yang Maha Esa. 
Penggunaan Model Picture And Picture Berbasis Multimedia Dengan Menginternalisasi Pendidikan Karakter Pada Pelajaran Pendidikan Kewarganegaraan

$\begin{array}{lrr}\text { Ruang } & \text { lingkup } & \text { Pendidikan } \\ \text { Kewarganegaraan (PKn) } & \text { meliputi } \\ \text { Pancasila, Nasionalisme } & \text { (Bangsa dan } \\ \text { identitas } & \text { nasional), } & \text { Negara, }\end{array}$

Kewarganegaraan, Konstitusi, Good Govermance, Pemerintah dan Pemerintahan, Hubungan Sipil-Militer, Hubungan Agama dan Negara, Masyarakat Madani, Demokrasi dan Hak Asasi Manusia (Sofhian, 2011).

Tujuan Pendidikan Kewarganegaraan adalah untuk membentuk karakter warga Negara yang baik. Selain itu, perlunya PKn diajarkan di sekolah dasar adalah agar siswa mampu memahami dan melaksanakan hak dan kewajiban untuk menjadi warga Indonesia yag cerdas, terampil, dan berkarakter sesuai dengan Pancasila dan UUD 1945, serta memahami nilai-nilai kedisiplinan, kejujuran, serta sikap yang baik terhadap sesama manusia.

Penelitian ini bertujuan untuk mengetahui penggunaan Model Picture and Picture menggunakan multimedia dengan menginternalisasi pendidikan karakter pada mata pelajaran Pendidikan Kewarganegaraan materi Lambang Negara. Melalui penelitian diharapkan siswa semakin bagus dalam menerima pelajaran dan meningkatkan penegtahuan karakter, sehingga mereka dapat memahami pelajaran sekaligus membangun karakter anak didik.

\section{Metode Penelitian}

Jenis penelitian yang dilakukan adalah Penelitin Tindakan Kelas (PTK). Adapun subjek dalam Penelitian Tindakan Kelas (PTK) ini adalah siswa kelas IV SDN 048232 Kabanjahe Tahun Pelajaran 2015/2016. Objek penelitian ini adalah hasil belajar siswa dalam pelajaran PKn menggunakan Model Picture And Picture Berbasis Multimedia Dengan Menginternalisasi Pendidikan Karakter pada mata pelajaran PKn pokok bahasan Lambang Negara Indonesia.
Teknik pengumpulan data dalam penelitian ini menggunakan Lembar Observasi Guru dan Lembar observasi kegiatan siswa.

Teknik analisis data menggunakan observasi dilakukan untuk mengetahui kesesuaian tindakan yang dilakukan dengan rencana yang telah disusun, sehingga dapat diketahui apakah pelaksanaan tindakan yang dilakukan menghasilkan perubahan sesuai dengan yang diinginkan. Untuk menganalisis hasil observasi terhadap aktivitas guru ditentukan dengan rumus:

$$
\mathrm{HP}=\frac{\text { jumiah Hasil Observasi }}{\text { jumlah Butir Pengamatan }}
$$

(Piet A.Sahertian, 2013)

Kriteria terhadap penilaian aktivitas guru ditunjukkan pada Tabel 1 berikut ini:

Tabel 1. Kriteria Penilaian dalam Pelaksanaan Pembelajaran Aktivitas Guru (Piet A.Sahertian, 2013)

\begin{tabular}{ll}
\hline Kriteria Penilaian & Keterangan \\
\hline$A=81-100 \%$ & Baik Sekali \\
\hline$B=61-80 \%$ & Baik \\
\hline$C=41-60 \%$ & Cukup \\
\hline$D=21-40 \%$ & Kurang \\
\hline$E=0-20 \%$ & Sangat Kurang \\
\hline
\end{tabular}

Sedangkan untuk mengetahui pelaksanaan pembelajaran aktivitas siswa digunakan rumus :

$$
\text { Nilai Siswa }=\frac{\text { Shor Perolehan }}{\text { Shor Maksimum }} \times 100
$$

(Asep Jihad dan Abdul Haris, 2012)

Kriteria terhadap penilaian aktivitas siswa ditunjukkan pada Tabel 2 berikut ini. 
Tabel 2. Kriteria Penilaian dalam

Pelaksanaan Pembelajaran Aktivitas Siswa

(Asep Jihad, 2012)

\begin{tabular}{ll}
\hline Kriteria Penilaian & Keterangan \\
\hline $1=10-29$ & Sangat Kurang \\
\hline $2=30-49$ & Kurang \\
\hline $3=50-69$ & Cukup \\
\hline $4=70-89$ & Baik \\
\hline $5=90-100$ & Sangat Baik \\
\hline
\end{tabular}

Penilaian terhadap hasil belajar siswa dengan cara menentukan: 1) penilaian individual siswa, 2) ketuntasan belajar siswa dan 3) nilai rata - rata kelas .

Penentuan penilaian individual siswa menggunakan rumus:

$$
K B=\frac{T}{T t} X 100 \%
$$

(Trianto, 2010:241)

Keterangan :

$\mathrm{KB}=$ Ketuntasan Belajar

$\mathrm{T}=$ Jumlah Skor Yang diperoleh Siswa

$\mathrm{Tt}=$ Jumlah Skor Total

Penentuan ketuntasan belajar siswa secara klasikal dengan menggunakan rumus :

$$
\mathrm{P}=\frac{2 \text { siswa tuntas belajar }}{2 \text { siswa }} \times 100 \%
$$

(Zainal Aqib,dkk, 2010)

Penentukan nilai rata-rata kelas dengan rumus :

$$
\bar{x}=\frac{\sum f i x i}{\sum f i}
$$

(Sudjana, 2005)

Keterangan :

$\bar{X} \quad=$ nilai rata-rata

$\sum f i . x i=$ jumlah semua nilai siswa

$\sum f i=$ jumlah siswa

\section{Hasil Penelitian dan Pembahasan}

Berdasarkan hasil penelitian pada siklus I diketahui pelaksanaan pembelajaran aktivitas guru 53,33\% (kriteria cukup) karena belum memenuhi standar ketentuan pelaksanaan pembelajaran yaitu minimal 75\% (kriteria baik). Sedangkan aktivitas siswa 58,33 (kriteria cukup) karena belum memenuhi standar ketentuan pelaksanaan pembelajaran yaitu, minimal 75 (kriteria baik) dengan menerapkan Model Picture And Picture Berbasis Multimedia dengan Menginternalisasi Pendidikan Karakter pada Mata Pelajaran PKn Pokok Bahasan Lambang Negara di Kelas IV SD Negeri 040448 Kabanjahe Tahun Pelajaran 2016/2017.

Berdasarkan hasil penelitian pada siklus II dapat diketahui pelaksanaan pembelajaran aktivitas guru $77,83 \%$ (kriteria baik karena sudah memenuhi standar ketentuan pelaksanaan pembelajaran yaitu minimal 75\% (kriteria baik), dan pada aktivitas siswa 86,66 (kriteria baik) karena sudah memenuhi standar ketentuan pelaksanaan pembelajaran yaitu 75 (kriteria baik) dengan menerapkan Model Picture And Picture Berbasis Multimedia dengan Menginternalisasi Pendidikan Karakter pada Mata Pelajaran PKn Pokok Bahasan Lambang Negara di Kelas IV SD Negeri 040448 Kabanjahe Tahun Pelajaran 2016/2017.

Secara ringkas hasil observasi dapat dilihat pada tabel berikut ini:

\begin{tabular}{|c|c|c|c|c|}
\hline Tahapan & $\begin{array}{l}\text { Aktiv } \\
\text { itas } \\
\text { Guru }\end{array}$ & Kriteria & $\begin{array}{l}\text { Aktiv } \\
\text { itas } \\
\text { Siswa }\end{array}$ & $\begin{array}{l}\text { Krit } \\
\text { eria }\end{array}$ \\
\hline Siklus & & & 58,33 & Cuk \\
\hline 1 & $53,33 \%$ & Cukup & $\%$ & up \\
\hline Siklus & & & 86,66 & \\
\hline 2 & $77,83 \%$ & Baik & $\%$ & Baik \\
\hline
\end{tabular}

Tabel 3. Hasil Observasi aktivitas Siswa dan Guru 
Penggunaan Model Picture And Picture Berbasis Multimedia Dengan Menginternalisasi Pendidikan Karakter Pada Pelajaran Pendidikan Kewarganegaraan

Hasil observasi dalam bentuk diagram batang disajikan dalam gambar berikut ini:

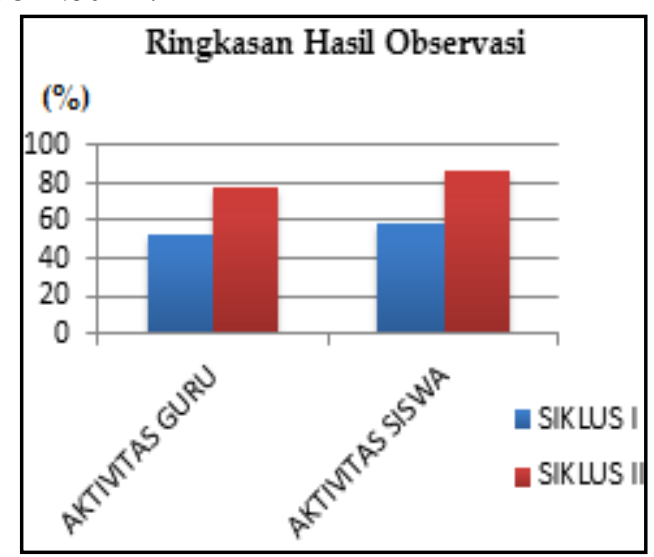

Gambar 1. Hasil Observasi Guru dan Siswa

Dengan demikian, maka pelaksanaan pembelajaran dengan menerapkan Model Picture And Picture Berbasis Multimedia dengan Menginternalisasi Pendidikan Karakter pada Mata Pelajaran PKn Pokok Bahasan Lambang Negara di Kelas IV SD Negeri 040448 Kabanjahe Tahun Pelajaran 2016/2017 tergolong Kriteria baik.

Dari pelaksanaan pembelajaran siklus I, dari 49 orang siswa jumlah siswa yang tuntas secara klasikal 30 (61,22\%) siswa dan dari 49 siswa jumlah siswa yang tidak tuntas $19 \quad(38,78 \%)$ dengan Menerapkan Model Picture And Picture Berbasis Multimedia dengan Menginternalisasi Pendidikan Karakter pada Mata Pelajaran PKn Pokok Bahasan Lambang Negara di Kelas IV SD Negeri 040448 Kabanjahe Tahun Pelajaran 2016/2017 belum tuntas secara klasikal karena dimana suatu kelas dikatakan tuntas belajar secara klasikal jika di dalam kelas tersebut terdapat $85 \%$ siswa yang sudah tuntas belajar sedangkan rata-rata yang diperoleh adalah 69,79 .

Siklus II dari 49 orang siswa jumlah siswa yang tuntas secara klasikal 45 $(91,83 \%)$ siswa dan dari 49 siswa jumlah siswa yang tidak tuntas $4(8,17 \%)$ dengan menerapkan Model Picture And Picture
Berbasis Multimedia dengan Menginternalisasi Pendidikan Karakter pada Mata Pelajaran PKn Pokok Bahasan Lambang Negara di Kelas IV SD Negeri 040448 Kabanjahe Tahun Pelajaran 2016/2017 karena suatu kelas dikatakan tuntas belajar secara klasikal jika di dalam kelas tersebut terdapat $85 \%$ siswa yang sudah tuntas belajar sedangkan rata-rata yang diperoleh adalah 85,30 . Secara ringkas hasil penelitian dapat dilihat pada Tabel 4 berikut ini.

Tabel 4. Hasil Belajar Siswa

\begin{tabular}{ccc}
\hline Tahapan & $\begin{array}{c}\text { Tun } \\
\text { tas }\end{array}$ & $\begin{array}{c}\text { Tidak } \\
\text { Tuntas }\end{array}$ \\
\hline Siklus I & $61,22 \%$ & $38,78 \%$ \\
\hline Siklus II & $91,83 \%$ & $8,17 \%$ \\
\hline
\end{tabular}

Hasil penelitian dalam bentuk diagram batang disajikan dalam Gambar 2 berikut ini:

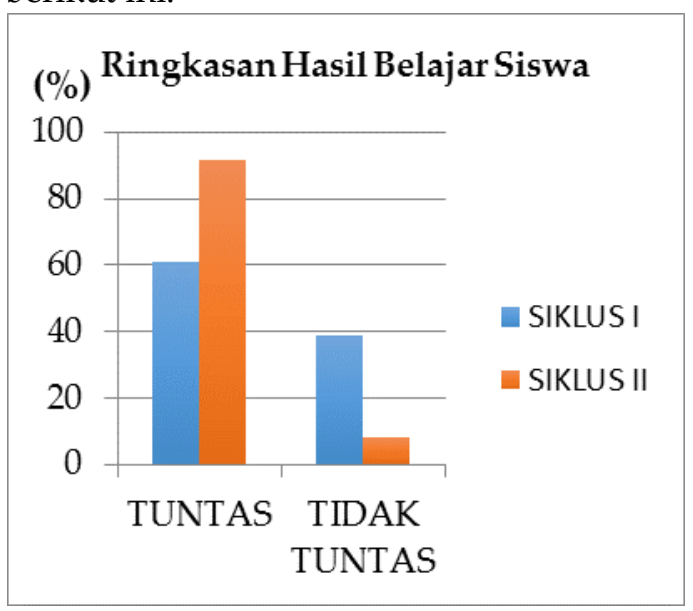

Gambar 2. Hasil Belajar Siswa

Dengan demikian hasil belajar siswa dengan menerapkan Model Picture And Picture Berbasis Multimedia dengan Menginternalisasi Pendidikan Karakter pada Mata Pelajaran PKn Pokok Bahasan Lambang Negara di Kelas IV SD Negeri 040448 Kabanjahe Tahun Pelajaran 2016/2017 meningkat dan tuntas secara klasikal.

Dari hasil di atas dapat dilihat peningkatan aktivitas siswa dari siklus 1 ke siklus 2 sebesar 28,33\%, hal ini setelah 
memperbaiki hasil observasi dan rekaman pelaksaanaan pembelajaran pada siklus 1 , guru memperbaiki proses pelaksanaan pembelaajarannya dengan melibatkan siswa lebih aktif dan selalu memotivasi siswa agar lebih giat belajar. Hal ini juga dapat dilihat dari segi peningkatan aktivitas guru.

Dari segi hasil belajar siswa dapat dilihat peningkatan ketuntasan belajar klasikalnya, dimana terjadi peningkatan sebesar 30,61\%. Ini juga dipengaruhi aktivitas yang meningkat sehingga siswanya dapat memahami materi ajar lebih baik dan guru memperbaiki proses mengajarnya.

\section{Simpulan dan Saran}

Hasil pada siklus I diketahui pelaksanaan pembelajaran aktivitas guru 53,33\% (kriteria cukup) Sedangkan aktivitas siswa 58,33 (kriteria cukup). hasil penelitian pada siklus II dapat diketahui pelaksanaan pembelajaran aktivitas guru 77,83\% (kriteria baik karena sudah memenuhi standar ketentuan pelaksanaan pembelajaran yaitu minimal $75 \%$ (kriteria baik), dan pada aktivitas siswa 86,66 (kriteria baik).

Pada Siklus I siswa yang sudah tuntas belajar rata-rata yang diperoleh adalah 69,79. Sedangkan pada siklus II siswa yang sudah tuntas belajar rata-rata yang diperoleh adalah 85,30. Dengan demikian hasil belajar siswa dengan menerapkan Model Model Picture And Picture Berbasis Multimedia Dengan Menginternalisasi Pendidikan Karakter pada Mata Pelajaran PKn Pokok Bahasan Lambang Negara di Kelas IV SD Negeri 040448 Kabanjahe Tahun Pelajaran 2016/2017 meningkat dan tuntas secara klasikal.

Kepada guru yang berencana menggunakan model pembelajaran ini, pada saat melakukan percobaan waktu banyak terbuang karena siswa belum memahami langkah-langkah percobaan. Diharapkan guru harus terlebih dahulu mendemonstrasikan langkah-langkah percobaan yang akan dilakukan siswa agar siswa paham. Sebelum model ini diterapkan, sebaiknya memahami terlebih dahulu tiap fase atau sintaks dari model Picture and Picture sehingga model pembelajaran ini dapat diterapkan dengan benar. Kondisi kelas akan selalu ribut bila tidak diberi penegasan sehingga dapat mengurangi efektivitas belajar dalam kelas, guru bisa lebih tegas dalam memberikan tugas terhadap siswa, agar pembelajaran yang berjalan lebih kondusif dan berjalan sesuai dengan rencana pembelajaran yang sudah dirancang.

\section{Daftar Pustaka}

Arikunto, S. dkk. 2012. Penelitian Tindakan Kelas. Jakarta: Bumi Aksara.

Arsyad. A. 2013. Media Pembelajaran, Jakarta: PT Raja Grafindo Persada.

Dimyati dan Mudjiono. 2013. Belajar dan Pembelajaran. Jakarta: PT Rineka Cipta.

Fathurrohman dan M. Sobry Sutikno, 2007. Strategi Belajar Mengajar. Bandung: PT.Refika Aditama.

Fathurrohman, M. 2015. Model-Model Pembelajaran Inovatif. Jakarta: AR.Ruzz Media.

Hamdani, 2011. Strategi Belajar Mengajar. Bandung: Pustaka Setia.

Hofstetter, Fried T. 2001, Multimedia Literacy. Third Edition. McGraw-Hill International Edition: New York.

Istarani, 2011, 58 Model Pembelajaran Inovatif (Referensi Guru Dalam Menentukan Model Pembelajaran) Medan: Media Pustaka

Jihad, Asep dan Abdul Haris. 2013. Evaluasi Pembelajaran. Yogyakarta: Multi Pressindo.

Muslich, Masnur. 2011. Melaksanakan PTK itu Mudah. Jakarta: PT Bumi Aksara.

Piet A Sahertian, 2010. Konsep Dasar dan Tehnik Supervisi Pendidikan dalam Rangka Pengembangan Sumber Daya Manusia.Jakarta:PT Rineka Cipta.PS

Purwanto. 2011. Evaluasi Hasil Belajar. Surakarta: Pustaka Pelajar. 
Penggunaan Model Picture And Picture Berbasis Multimedia Dengan Menginternalisasi Pendidikan Karakter Pada Pelajaran Pendidikan Kewarganegaraan

Sekretariat Direktoral Jendral Pendidikan

Dasar Kementerian Pendidikan

Nasional. 2011. Mencari Karakter Terbaik dari Belajar Sejarah. Jakarta: Kementerian Pendidikan Nasional.

Sekretariat Direktoral Jendral Pendidikan Dasar Kementerian Pendidikan Nasional, 2011. Pendidikan Karakter dalam Pembelajaran PKn. Jakarta: Kementerian Pendidikan Nasional.

Sofhian,S dn Sahid.A, 2011. Pendidikan Kewarganegraan (Civiv Education) Pendidikan politik. Nasionalisme dan Demokrasi. Bandung Fokusmedia.

Trianto. 2011. Mendesain Model Pembelajaran Inovatif Progresif Konsep, Landasan dan Implementasinya pada Kurikulum Tingkat Satuan Pendidikan (KTSP). Jakarta: Kencana Prenada Media Group.

UU No 12 Tahun 2012 Tentang Sistem Pendidikan Nasional.

Zainal Aqib, 2011. Pendidikan Karakter Membangun Perilaku Positif Anak Bangsa. Bandung: CV.Yrama widya. 